\title{
Fighting to the end: African Americans and end of life care decisions
}

\author{
Apollo Townsend Stevens* \\ Director of Hospice Home, Transitions LifeCare, Raleigh, NC 27607, USA
}

\begin{abstract}
Statistics demonstrate that African Americans generally choose aggressive treatment at end of life. Hospice care is an alternative to aggressive treatment; however, research literature is replete with studies describing the potential barriers to African American choice of hospice care at end of life. One such reported barrier is spiritual beliefs that are incongruent with hospice philosophy. Case studies may shed further light on end of life care choices within this population: presented in this article is the medical journey of one African American woman after she received a terminal diagnosis. This case study presents the possibility that African American pursuit of aggressive treatment at end of life may be a spiritual decision versus a medical one.
\end{abstract}

\section{Problem and significance}

African Americans comprise about $12 \%$ of the United States (US) population but less than $10 \%$ use hospice services at end of life $[1,2]$. Of persons ages 65 and older in the US, $22 \%$ of African Americans use hospice vs. $29 \%$ of Caucasians [2]. African Americans are more likely to choose to continue to receive what is considered to be aggressive treatment, even after a terminal disease has been diagnosed. A random, stratified sample of Medicare decedents records, (sample taken from 2001 Medicare records, $\mathrm{N}=158,780$ ) showed significant cultural differences in Medicare spending for life-sustaining interventions and hospice care in the last 6 months of life. Blacks were more likely to choose aggressive care and hospital intensive care units more than twice as much as Whites: $10.5 \%$ compared to $4.1 \%$ and per patient costs averaged $\$ 20,166$ for Whites versus $\$ 26,704$ for Blacks [3]. Over a decade later, health care costs are significantly higher, hospitals are facing reduced Medicare payment for excess readmissions as part of the 2010 Affordable Care Act [4], and efforts to decrease repeat hospitalizations for heart failure and pneumonia (conditions that are often seen in hospice patients) are being implemented across the US. Hospice provides a specialized alternative to hospitalization: an interdisciplinary team provides end of life care, primarily in the patient's home; care focuses on symptom management and emotional/ spiritual support for the patient and caregivers. Hospice services are covered by Medicare, Medicaid, and private insurers at a fraction of the cost of intensive hospital treatment [5]. These services are available across the US. However, the literature documents several barriers to the use of hospice services by African Americans. Spiritual beliefs that are incongruent with hospice philosophy are often cited as one of those barriers. Sensitivity to, and acceptance of, African American spiritual beliefs by health care providers may have a significant impact on end of life care choices in this patient population. A case study is presented to demonstrate how two physicians interacted with an African American woman and how those physician-patient interactions shaped the woman's care choices at end of life.

\section{Literature review}

Research literature documents several potential barriers to hospice use by African Americans. A lack of culturally competent care is cited as a barrier $[1,6]$. A preference to continue cancer treatment (chemotherapy) versus a "comfort measures only" approach is a deterrent to use of hospice [7]. Lack of knowledge about hospice $[8,9]$, and the lack of cultural diversity of the care team [6] are also documented barriers to choosing hospice care. However, the most commonly reported factor deserves serious consideration: the spiritual beliefs of African Americans. Johnson et al. [10] reported that African Americans were more likely to have spiritual beliefs that are in conflict with the goals of a palliative plan of care. Further, a literature review, conducted by Mitchell [11] suggests health care personnel need an awareness of the impact that spirituality/religion may have in the care decisions of African American patients at end of life. A case study is presented to increase the awareness of the influence spiritual beliefs may have on treatment decisions in this population.

\section{Case study}

The only symptom was a moist cough that would not go away. Three weeks later, the diagnostic tests showed advanced stage IV adenocarcinoma of the lung. This African American woman had never really been sick her entire life, and she had never smoked; but her husband had. The years of breathing in second hand smoke had caught up with her in a lethal way. A strong woman of faith, her response to the diagnosis was "God's got this." Her assurance of God's never-failing love and healing power remained at the forefront of every conversation, and every health care decision, over the next several months.

A prominent, well-respected member of a large African American church, Gloria's (fictitious name) strong faith, generosity of spirit, and genuine love for people brought smiles to the faces of everyone who

Correspondence to: Apollo Townsend Stevens, DNP, RN, Director of Hospice Home, Transitions LifeCare, Raleigh, NC 27607, USA, Tel: 614-562-9731; E-mail: atownsend@transitionslifecare.org

Keywords: African American, spirituality, hospice, palliative care, end of life

Received: May 07, 2016; Accepted: May 17, 2016; Published: May 20, 2016 
knew her. Gloria was known for her listening ear and sound, biblical advice. She could be counted on to visit the sick and often prepared home cooked meals for families to help ease the stress of caring for a loved one. Gloria also taught Sunday school at the church she attended; she was viewed as the epitome of a "godly woman." The Sunday she announced that she had stage IV lung cancer, a shock wave went through the church. How could this possibly be happening to her? Suddenly, all eyes were focused on this woman: and everyone was asking "What is she going to do?" That question was answered in her usual way. She professed her steadfast faith in God and His ability to heal diseases. She also made an appointment with a well-respected oncologist in the area.

On Gloria's first visit, the oncologist told her that, if she followed his recommended treatment plan, he could give her two more years of life. While well-meaning, the statement was perceived by Gloria as beyond the capability of the practitioner. From her spiritual standpoint, Gloria believed in physicians as helpers in the healing process but only God could guarantee life. Out of respect for the physician, she did not voice how his statement affected her, but in the telling of her experience about the office visit she laughed and expressed how presumptuous the physician's words seemed to her. Gloria did, however, continue under his care and consented to chemotherapy treatments.

After two chemotherapy treatments, the tumor mass appeared to be shrinking. Gloria and the oncologist were hopeful and a third treatment was completed. But within days of receiving the third chemotherapy infusion, significant side effects began to appear: mouth sores, rash, abnormal blood counts, and a paralyzing fatigue. In one of our many telephone conversations, she made it clear she was stopping the chemotherapy. She said three treatments were all she had planned to do: "one for the Father, one for the Son, and one for the Holy Spirit." To Gloria, the unbearable side effects meant that it was now time to simply "trust God."

Gloria kept her word. She met with the oncologist and explained she was stopping the treatments. At that visit, when she explained the side effects were intolerable, the oncologist revealed that, in his zeal to arrest the cancer, he had given her higher than normal doses of the chemotherapeutic agents. He assured her subsequent treatments would not be as potent and urged Gloria to continue the therapy. Gloria voiced her surprise that the treatment dosages were higher than originally agreed and expressed her disappointment that the physician did not discuss this course of action with her prior to treatment. The physician apologized but continued to press for further treatments. Gloria refused. She also let the oncologist know that, from that point forward, her primary care physician (PCP) would be managing her care.

Gloria's care was resumed by her PCP. Fortunately, her PCP was well aware of her strong spiritual beliefs and fully realized the need to incorporate those beliefs into his approach. He genuinely respected the fact that his patient saw God as the Divine Healer, and that she believed God was totally capable of miraculously ridding her of cancer. He kept this knowledge in the forefront of every discussion surrounding care options, and even told her he would be praying for her. After several discussions about the benefits of chemotherapy, the PCP accepted that Gloria was resolute in her decision.

Over the next several months, Gloria and her PCP worked together to palliate her symptoms. She spoke of finding great comfort in the care and concern her PCP demonstrated toward her. Throughout the disease process, Gloria never hesitated to call her PCP with her symptoms or concerns. There were good days and some "not so good" (her words). The good days were the days she could breathe, complete most of the tasks she wanted to do, and spend time with all those who loved her. The not so good days were marked by shortness of breath, the need to use oxygen, and pleural taps to remove the fluid that was rapidly building up. Her conversation always included words of faith and declarations of the goodness of God.

The day came when Gloria could only talk a few minutes; she was too weak. She shared she was working on completing some "important papers." She told me her family would arrive soon: she had asked them to come over so she could talk to them. Gloria had been in communication with her PCP and they had both decided it was time for hospice. Her plan was to explain to her family that she had not "given up" but that she needed the support of professionals trained in palliative care; she said she had experienced such positive results in the advice that her PCP had offered, and now realized more intensive hospice intervention was needed. She emphasized she would continue to "fight" the cancer, and to "believe God" for her healing; and hospice would know what to do to help her breathing. Her PCP had arranged for her to be admitted that night to the hospice inpatient unit at the hospital.

The final days of this courageous woman were spent in the hospice inpatient unit. By the time she was admitted to the unit, she was only able to speak in a whisper, and she was very weak. I went to the unit to visit her. Another visitor from the church was there, too. She and I sat by Gloria's bed and talked about cheerful bits of church news that brought faint smiles to the patient's face. Gloria was comfortable: she had no pain, and there was no struggling to breathe. We chatted quietly until Gloria fell asleep. She died early Easter Sunday morning.

\section{Discussion}

Every patient care experience is different. Health care professionals are challenged, with each patient encounter, to provide individualized, patient-specific care. Bentacourt et al. [12] documented the emergence of the movement toward the provision of culturally competence within the healthcare system: insurance companies, schools of learning, and healthcare providers began to understand the impact of cultural beliefs on healthcare decisions and health outcomes around the year 2002. Since that time, the body of evidence has grown tremendously, and healthcare providers are increasingly aware that a patient's cultural beliefs must be taken into consideration when mapping a plan of care. Cultural awareness and cultural competence add to a clinician's ability to provide individualized care in any setting [13]. In the case study example, the oncologist could have benefitted from awareness that his African American patient might have a strong cultural belief in the healing power of God and that chemotherapy would be viewed as an augment to prayer and faith. The clinician could have established a stronger physician-patient relationship with Gloria by asking questions about her cultural beliefs and acknowledging those beliefs. If he had taken this approach from the beginning, he possibly would have had a better understanding of how Gloria's beliefs might impact care planning and care choices. The oncologist also should not have increased the dosage of the chemotherapy without talking to the patient first. Communication is critical for any patient encounter but especially for patients with African American heritage. African Americans have a strong mistrust of the healthcare system because of past abuses; it is imperative for all clinicians to be open and honest with African American patients about treatment options prior to implementation [14-17]. By contrast, Gloria's PCP seemed to have a much better 
understanding of how cultural beliefs can shape patient decisions and approaches to healthcare. The PCP not only acknowledged Gloria's beliefs but he also offered to pray for her. Research suggests a clinician's bedside manner may determine whether or not patients will trust that the clinician has the patient's best interest at heart [14]. The physicianpatient bond was such that the PCP met no resistance when the recommendation came to choose hospice care. With her physician's support, Gloria was able to mesh her spiritual beliefs and hospice care. She made it clear to everyone (her PCP, family, and church) that she would continue to "fight" the disease while receiving comfort measures only under the care of hospice.

While individual clinicians may benefit from this case study, Gloria's experience may also provide some insight for hospice programs. As stated previously, spirituality, as a cultural construct, is well-documented in the literature as a determining factor in African American decision-making regarding hospice care. Hospices have a unique opportunity to design and implement patient care plans that embrace the spiritual beliefs of African Americans. Instead of a "one size fits all" hospice philosophy, hospices may find that offering certain treatment options, concurrent with traditional hospice care, may open the door to enrolling more African American patients in hospice programs. For example, Gloria decided almost immediately after receiving the stage IV diagnosis that she would "trial" three chemotherapy treatments ("one for the Father, one for the Son, and one for the Holy Spirit"). At that moment, the potential existed for Gloria to enroll in a hospice program and receive limited chemotherapy treatments along with palliation of the chemotherapy side effects. Hospice care would also have afforded Gloria and her family the benefit of emotional and spiritual support from the hospice interdisciplinary team throughout the process. Expanded care options by hospices may convey an understanding of the African American cultural belief that it is appropriate to "fight" to overcome disease processes, no matter how advanced the disease may be. In other words, for hospices to be able to reach greater numbers of African Americans at end of life, hospices may want to explore the concept that, for African Americans, pursuing aggressive treatment at end of life may represent a spiritual choice, not a medical choice.

\section{References}

1. Winston CA, Leshner P, Kramer J, Allen G (2004) Overcoming barriers to access and utilization of hospice and palliative care services in African-American communities. Omega 50: 151-163.
2. NHPCO's Facts and Figures: Hospice Care in America (2014). Retrieved from http:// www.nhpco.org/sites/default/files/public/Statistics_Research/2014_Facts_Figures.pdf

3. Hanchate A, Kronman AC, Young-Xu Y, Ash AS, Emanuel E (2009) Racial and ethnic differences in end-of-life costs: why do minorities cost more than whites? Arch Intern Med 169: 493-501. [Crossref]

4. Reinhard SC (2012) Reforming Medicare. In D. J. Mason, J. K. Leavitt, \& M. W Chaffee (Eds.), Policy \& politic in nursing and health care. St. Louis, MO: Elsevier Saunders (pp. 162-168).

5. Martin JP (2012) Home care and hospice: Evolving policy. In D. J. Mason, J. K Leavitt, \& M. W. Chaffee (Eds.), Policy \& politic in nursing and health care. St. Louis, MO: Elsevier Saunders (pp. 214-219).

6. Yancu CN, Farmer DF, Leahman D (2010) Barriers to hospice use and palliative care services use by African American adults. Am J Hosp Palliat Care 27: 248-253. [Crossref]

7. Fishman J, O'Dwyer P, Lu HL, Henderson H, Asch DA, et al. (2009) Race, treatment preferences, and hospice enrollment: eligibility criteria may exclude patients with the greatest need for care. Cancer 115: 689-697.

8. Ache KA, Shannon RP, Heckman MG, Diehl NN, Willis FB (2011) A preliminary study comparing attitudes toward hospice referral between African American and white American primary care physicians. Journal of Palliative Medicine 14: 542-547.

9. Townsend A, March AL, Kimball J (2015) Can faith and hospice coexist: Is the African American church the key to increased hospice utilization for African Americans? Journal of Transcultural Nursing.

10. Johnson KS, Kuchibhatla M, Tanis D, Tulsky JA (2008) Racial differences in hospice revocation to pursue aggressive care. Arch Intern Med 168: 218-24. [Crossref]

11. Mitchell BL, Mitchell LC (2009) Review of the literature on cultural competence and end-of-life treatment decisions: the role of the hospitalist. Journal of the National Medical Association 101: 920-926.

12. Betancourt JR, Green AR, Carrillo JE, Park ER (2005) Cultural competence and health care disparities: key perspectives and trends. Health Aff (Millwood) 24: 499-505. [Crossref]

13. Centers for Disease Control (2015) Sexually Transmitted Diseases Treatment Guidelines

14. Jacobs EA, Rolle I, Ferrans CE, Whitaker EE, Warnecke RB (2006) Understanding African Americans' views of the trustworthiness of physicians. J Gen Intern Med 21: 642-647. [Crossref]

15. U.S. Public Health Service Syphilis Study at Tuskegee: Tuskegee Timeline. Retrieved from: http://www.cdc.gov/tuskegee/timeline.htm

16. African American Outreach Guide (2016). Retrieved from: http://www.nhpco.org/sites default/files/public/Acess/African_American_Outreach_GuideFull.pd

17. Cultural Competence (2015). Retrieved from: https://npin.cdc.gov/pages/culturalcompetence

Copyright: (2016 Stevens AT. This is an open-access article distributed under the terms of the Creative Commons Attribution License, which permits unrestricted use, distribution, and reproduction in any medium, provided the original author and source are credited. 